\title{
PENGARUH LANINA TERHADAP PELAYARAN DAN UPAYA MENGATASI KESELAMATAN KAPAL DI SAMUDERA INDONESIA
}

\author{
Subandi ${ }^{1)}$ \\ 1) Jurusan Nautika AKPELNI Semarang
}

\section{PENDAHULUAN}

Dalam suatu pelayaran kapal pada lintang kurang lebih $11^{\circ}-00^{\circ}$ utara maupun lintang Selatan akan menjumpai akan adanya cuaca buruk (badai). Dalam cuaca buruk ada kalanya kapal mengalami rolling (goyang kiri kanan); pitching (ngetrail); heawing (gerakan keatas dan kebawah); surging (maju mundur); swaying (mengayun kiri kanan) dan yawing (memutar kiri kanan), yang dapat menghambat jalannya pelayaran maupun menyebabkan kerusakan-kerusakan.

Cuaca buruk adalah salah satu faktor keadaan laut yang mempengaruhi olah gerak kapal. Adapun yang dimaksud cuaca buruk adalah keadaan laut yang buruk, disebabkan karena angin, ombak dan lain-lain, sehingga para Perwira kapal harus dapat membawa kapalnya sebaik-baiknya dalam mengatasi situasi seperti ini.

Lanina adalah akibat fenomena alam yang terjadinya pada suatu saat tertentu yang dalam waktu tidak dapat ditentukan secara pasti. Hal ini adanya mencairnya gunung es dari kedua kutub dibumi ini. Dengan pasangnya air laut terbesar menimbulkan Rough sea (ombak besar) merupakan cuaca buruk bagi pelayaran kapal-kapal.

Cara terbaik bagaimana mengolah gerak dari kapal pada cuaca buruk sangat tergantung pada type, ukuran dan kemampuan dari sarana-sarana olah gerak yang dimilikinya.

Seorang perwira kapal akan mengenal karakter dan kemampuan kapalnya, serta sejauh mana kapal itu sanggup diolah gerak tanpa menimbulkan bahaya terhadap keselamatan jiwa, muatan serta kapalnya.

Sebagaimana kita ketahui bahwa jauh sebelum memulai suatu pelayaran setiap kapal harus dipersiapkan laik laut, termasuk didalamnya pengikatan secara baik barangbarang yang mudah bergerak dengan perhitungan bahwa begitu kapal meninggalkan pelabuhan langsung menghadapi cuaca buruk.

\section{PERMASALAHAN}

Berdasarkan pemikiran yang dipaparkan pada bagian pendahuluan ini, dapatlah dikemukakan dalam dua permasalahan sebagai beriku:

1. Bagaimana pengaruh Lanina terhadap pelayaran di laut?

2. Bagaimana upaya untuk mengatasi keselamatan kapal di Samudera Indonesia?

\section{PEMBAHASAN MASALAH}

A. Lanina di Samudera Indonesia.

Diperkirakan pada suatu saat di Samudera Indonesia akan mendapat pengaruh dari mencairnya gunung-gunung es yang berada di kutub selatan akan membuat gelombang pasang terbesar menuju equator (BMG, 1998) dimana daerah equator yang mempunyai udara panas secara horizontal akan menuju ke daerah yang mempunyai udara dingin pada kutub selatan tersebut. Di belahan bumi utara arah angin menyimpang ke kanan dan di belahan bumi selatan arah angin menyimpang ke kiri terhadap arah gaya gradien tekanan udara berdasarkan hukum Buys Ballot I (Supangkat, 1991). Dengan pasangnya air laut tersebut untuk wilayah bagian selatan dari belahan bumi ini akan berhembus angin Cyclone di Samudera Indonesia selatan bagian Timur dan Samudera Indonesia Selatan bagian 
Barat. Dengan bertiupnya angin dari \pm lintang $11^{\circ}-00^{\prime}$ selatan menuju ke arah Barat, kemudian berbelok kearah Tenggara dengan berputar searah jarum jam. Dengan kata lain gerakan Cyclone tersebut dari daerah tropika sampai dengan daerah $s u b$ tropika (lintang $35^{\circ}-00^{\prime}$ selatan).

Cyclone itu akan berhenti sementara bilamana ia berada diantara daerah yang bertekanan udara tinngi (High pressure). Bisa jadi Cyclone itu stationary dan dapat menjadi bergerak lagi serta mempunyai kecepatan dan arah lebih dahsyat lagi.

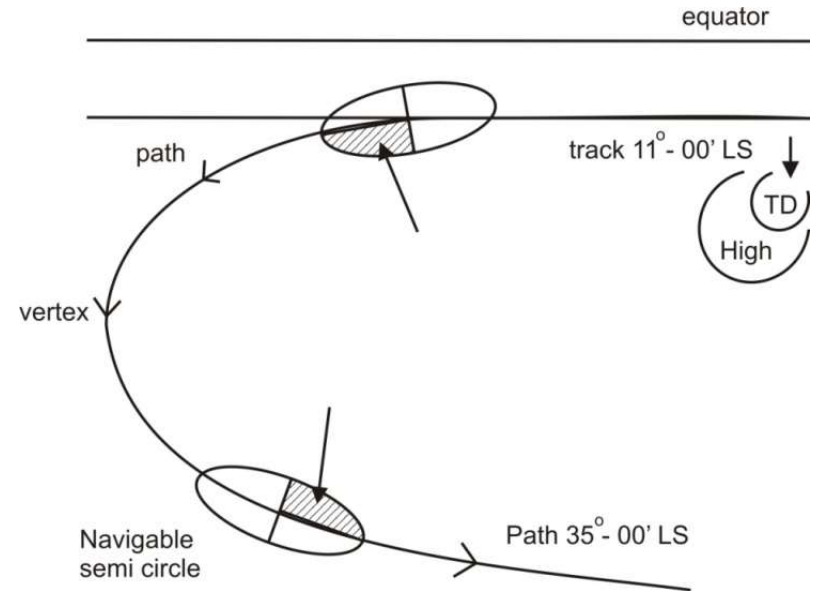

Gambar 1. Hukum Buys Ballot I

B. Pengaruh Lanina terhadap pelayaran.

Lanina sangat berpengaruh didalam analisis data dari cuaca dewasa ini. Sudah dapat dipelajari tentang cara-cara mendeteksi adanya cuaca buruk dengan menggunakan sarana navigasi seperti Barometer, Barograph, Anemometer, Facsimile serta berita navigasi radio dari stasiun-stasiun pantai. Didahului dengan timbulnya Cold-front dan warm-front, akhirnya menjadi Low pressure dan berubah menjadi Tropical Depression (TD) terus Tropical Storm akhirnya Cyclone, dimana pada belahan bumi Selatan gerakannya searah jarum jam, menurut hukum Buys Ballot II (Supangkat, 1991). Jika dideteksi sedemikian diketahui bahwa haluan yang akan ditempuh kapal melalui cuaca buruk, sebaiknya dihindari dengan cara berlindung atau shelter pada sebuah pulau atau ditempat yang aman untuk sementara waktu, yang kemudian melanjutkan perjalan kembali.

Lanina ini dapat menimbulkan kerusakan yang cukup fatal dilaut khususnya bagi pelayaran kapal-kapal. Amukan angin ribut seperti ini terutama pada atau didekat pusatnya dapat menenggelamkan kapal-kapal kecil atau kapal-kapal besar dapat rusak karenanya. Jauh sebelumnya harus dilakukan tindakan berjaga-jaga berupa pencegahan dalam waktu yang tepat, sebab satu kali keadaan angin dari laut buruk muncul, maka akan segera membesar secara cepat dan mungkin kapal telah menjadi sulit untuk bergerak ke tempat yang aman. 


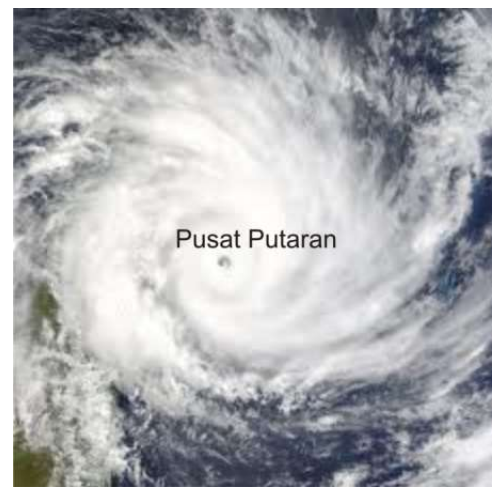

Gambar 2. Cyclone

C. Upaya Mengatasi Keselamatan Kapal Di Samudera Indonesia Akan Adanya Lanina Sebelum membicarakan upaya mengatasi keselamatan kapal di Samudera Indonesia akan adanya Lanina, perlu diketahui terlebih dahulu tentang :

1. Badai Putar Tropika (tropical depression) di Samudera

Ini biasa terjadi di samudera pada lintang $11^{\circ}-00^{\prime} \mathrm{S}$. jadi pada lintang $00^{\circ}-00^{\prime}$

$\mathrm{U}$ (equator) sampai lintang $11^{\circ}-00^{\prime}$ utara maupun selatan tidak akan kita temui badai dahsyat tersebut.

Tanda-tanda akan adanya badai putar (cyclone) sebagai berikut :

- Tekanan udara turun di bawah tekanan normal secara drastis

- Arah angin tidak menentu

- Sweel/alun kemana-mana

- Awan cirrus stratos

Syarat-syarat terbentuknya cyclone sebagai berikut :

- Berada di daerah tekanan udara tinggi sub tropis

- Suhu di atas air laut $27^{\circ} \mathrm{C}$

- Harus ada tekanan udara yang bergerak ke atas dengan cepat

Bila saatnya storm warnings perlu kiranya diwaspadai dengan diikuti cara pendataan yang cermat setiap jam, jangan sampai terjadi point collision; dimana akan berakibat fatal.

Badai potar tropika (cyclone) disamping mempunyai arah dan kecepatan, juga mempunyai moving (berputar) yang sangat cepat. Untuk gerakan kecepatan 10 knot $\rightarrow$ kecepatan putar $10 \mathrm{kt}$, gerakan kecepatan 23 knot $\rightarrow$ kecepatan putar $550 \mathrm{kt}$ dan gerakan kecepapatan $30 \mathrm{knot} \rightarrow$ kecepatan putar $700 \mathrm{kt}$.

Di bawah ini disajikan nama-nama dari badai putar meliputi daerah dan waktu terjadinya.

Tabel 1. Badai putar, daerah dan waktu terjadinya

\begin{tabular}{|l|l|l|}
\hline Daerah & Nama & Waktu (bulan) \\
\hline Lautan Atlantic Utara & Hurricane & Juni sampai Nopember \\
\hline Samudera Pasific Utara bagian timur & Cordonazo & Juni sampai Nopember \\
\hline Samudera Pasific Utara bagian barat & Typhoon & Juni sampai Nopember \\
\hline Samudera Pasific Selatan bagian barat & Hurrican & Desember sampai April \\
\hline Samudera Indonesia Selatan bagian timur & Willy-willy & Desember sampai April \\
\hline Samudera Indonesia Selatan bagian barat & Cyclone & Desember sampai April \\
\hline Teluk Bengal dan Laut Arabia & Cyclone & Juni sampai Nopember \\
\hline
\end{tabular}


Disebut badai putar tropical sebab munculnya atau gejala timbulnya badai tersebut mulai dari daerah tropika sampai dengan daerah sub tropika $\left(35^{\circ}-00^{\circ}\right.$ LU/LS) dengan arah dari timur ke arah barat terus menyimpang ke arah timur laut dan tenggara.

Pada belahan bumi bagian utara badai tersebut bergerak dan berputar berlawanan arah jarum jam serta muncul berkisar bulan Juni sampai Nopember sedangkan pada belahan bumi bagian selatan bergerak dan berputar searah jarum jam serta muncul bersidar bulan Desember sampai April setiap tahunnya.

2. Lanina serta terjadinya cuaca buruk

Berdasarkan pengamatan ahli meteorologi sebagian berpendapat bahwa lapisan ozon yang dekat atmosfir pada permukaan bumi mulai berkurang dan menurut data analisa yang ada, adanya lubang di atmosfir yang semakin membesar, dimana terjadi penguapan lebih cepat khusus pada kedua kutub bumi kita.

Mengingat daerah kutub utara (Greenland) dan kutub selatan (New Founland) yang terdiri sebagian besar berupa gunung-gunung es tertembus oleh sinar matahari, menyebabkan terjadinya bongkahan-bongkahan es yang akhirnya pecah dan mencair. Mencairnya es ini terjadilah pasang air terbesar dari daerah yang bertekanan udara tinggi (high) ke daerah yang bertekanan udara rendah (low).

Karena gunung-gunung es sebagian besar berada di kutub utara, maka menurut analisa pengamatan arus pasang air laut akan terbesar menuju ke arah selatan dekat equator (lintang selatan), khususnya di Samudera Indonesia selatan bagian timur dan Samudera Indonesia selatan bagian barat.

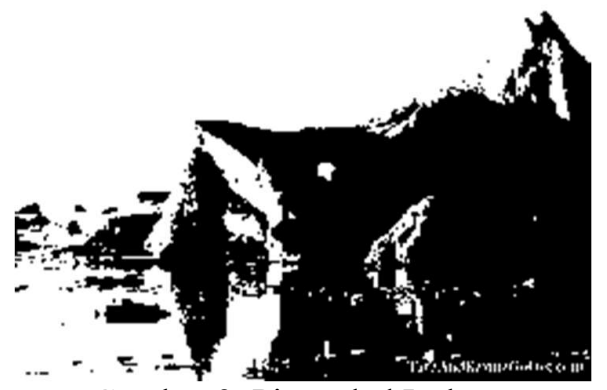

Gambar 3. Pinnacled Iceberg

Dimuka telah dikatakan bahwa Lanina diperkirakan suatu fenomena arus pasang yang cepat yang dapat menimbulkan gelombang pasang terbesar secara global di permukaan bumi bila dibandingkan dengan badai putar tropika yang bersifat lokal.

3. Melayarkan kapal dalam pengaruh Lanina

Sebelum berada pada cuaca buruk, maka segera dilakukan tindakan-tindakan sebagai berikut :

a. Jangkar diikat kuat, kuku masuk, ulup serta pipa-pipa udara ditutup rapat.

b. Palka ditutup rapat, roda diturunkan, dilasing serta keg dipasang disetiap ujung-ujungnya.

c. Semua souding pipe, air pipe, veltilation dalam keadaan tertutup, pasang tali kawat keamanan di dek untuk pegangan crew, batang pemuat dilasing kuat. 
d. Sekoci penolong dan barang-barang lain yang mudah bergerak dilasing kuat.

e. Kegiatan-kegiatan pemeliharaan yang tidak penting dihentikan, siapkan strom oil di sisi bawah angin.

f. Beritahukan seluruh anak buah kapal untuk mengikat barang-barang di kamar mesin, dapur, salon, kamar tidur dan lain-lain.

Setelah kapal berada dalam cuaca buruk bilamana :

a. Ombak dari lambung kapal

Ombak yang datang dari tempat melintang di lambung kapal, akan membuat kapal oleng (rolling).

Cara untuk mengurangi rolling kapal adalah dengan merubah haluan sedemikian agar tidak terjadi sinkronisme antara periode oleng kapal dengan periode gelombang semu. Hal ini dapat dihitung dengan rumus :

Dimana

$$
\mathrm{T}=\frac{0,44 \times \text { lebar }}{\sqrt{\mathrm{GM}}}
$$

$\mathrm{T}=$ waktu oleng kapal dalam detik

$0,44=$ tetapan

Lebar = lebar kapal

$\mathrm{GM} \quad=$ jarak titik berat kapal dengan titik metasentrum

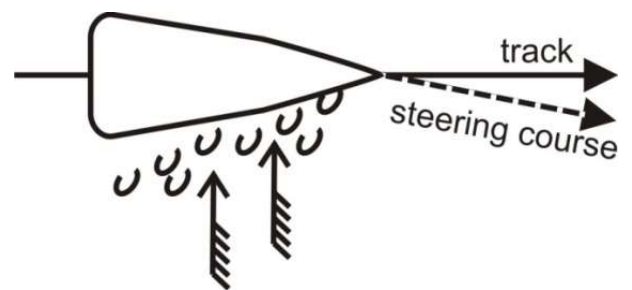

Gambar 4. Arah track dan steering course

b. Menghayutkan kapal dengan mesin stop

Cara seperti ini dapat dilakukan jika ruangan cukup menghanyutkan kapal, karena bukan hanya angin dan ombak akan membawa kapal ke sisi bawah angin tetapi akan membuat arus di permuakan. Hanyutnya kapal terbawa angin misalnya pada kekuatan angin gale dapat mencapai $2-3$ knots dan pada kekuatan angin cyclone bisa mencapai 5 knots. Jika kapal berada dekat atau pada pusat tropical storm maka cuaca akan menjadi kacau balau, angin datang dari segala arah sehingga tidak mungkin lagi menempatkan kapal untuk menyongsong ombak maupun mengikuti ombak.

Pada tropical storm ini dikenal daerah navigable semicircle dimana kapal akan ditarik ke dalam pusat pusaran.

Menurut pengalaman penyaji ketika masih menjalani profesi seorang pelaut di atas kapal, pernah berada pada situasi seperti itu, lebih baik mesin stop. Tentu saja kapal tersebut mengalami rolling dan pitching berat dengan kondisi stabilitas yang baik dan memiliki kekedapan yang cukup. 


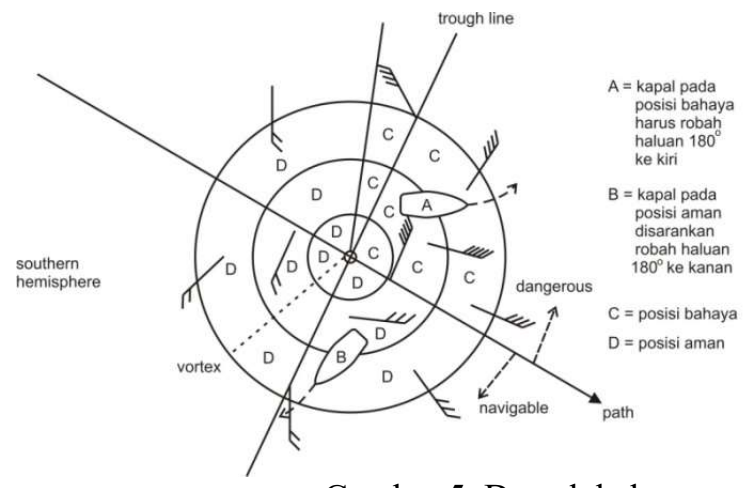

Gambar 5. Daerah bahaya cyclone

c. Hal-hal yang disarankan dan dihindari apabila kapal berada dalam cuaca buruk:

Sebagai pertimbangan dalam menghadapi cuaca buruk, berikut ini adalah halhal yang disarankan dan juga yang harus dihindari.

Disarankan :

1. Agar diusahakan mendapatkan informasi mengenai keadaan cuaca secara terus menerus

2. Mengetahui faktor-faktor pada stabilitas kapal pada waktu itu, dan ambil tindakan untuk memperbaiki stabilitas, bila dianggap perlu, sebelum menghadapi cuaca buruk.

3. Memperhatikan gejala-gejala dan tanda-tanda dari adanya storm dan segera mengambil tindakan-tindakan yang dianggap perlu.

4. Jika memungkinkan, rubah haluan pada waktu ombak, terutama jika panjang kapal hampir sama dengan panjang gelombang.

Dihindari :

1. Menggerakkan kapal terlalu cepat ke dalam gelombang, terutama kapalkapal yang berkecepatan tinggi dan ringan

2. Ragu-ragu dalam mengambil tindakan-tindakan yang bersifat segera untuk mengurangi kecepatan

3. Kecepatan kapal terlalu besar dalam berlayar mengikuti ombak, terutama jika panjang kapal hampir sama dengan panjang gelombang.

\section{KESIMPULAN}

1. Pengaruh lanina terhadap pelayaran di laut sangat berpengaruh sekali, karena di dalam melayarkan kapal terutama pada saat kapal diolah gerak senantiasa mendapat pengaruh dari faktor luar kapal. Faktor dari luar kapal meliputi : angin, arus dan ombak. Karena lanina itu terjadinya paa suatu saat tertentu dalam waktu tidak dapat ditentukan secara pasti dan menimbulkan cuaca buruk di laut, maka bisa menimbulkan bahaya yang besar antara lain kapal tenggelm dan hilang.

2. Upaya untuk mengatasi keselamatan kapal di Samudera Indonesia ketika terjadi lanina, senantiasa sebagai perwira jaga laut mendeteksi terus menerus melalui pesawat facimile dimana posisi lanina berada dengan mengeplot pada peta laut, berapa kecepatan putarnya, kecepatan bergerak serta arahnya. Sehingga dalam mengolah gerak kapal dapat diperhitungkan agar supaya posisi kapal dan posisi lanina pada suatu saat tidak bertemu. Apabila kapal telah mengetahui bahwa kan 
terjadi cyclone dan haluan kapal menuju ke tempat tersebut sebaiknya menghindari dengan cara berlindung / shelter di tempat yang aman setelah cuaca baik, baru melanjutkan perjalanan kembali.

\section{DAFTAR PUSTAKA}

CR Burgers, O.B.E, RN 1950. Meteorology for Seaman

F.J. Wyle. 1982. The Use of Radar at Sea, the Royal Institute of Navigation.

I.E.M. Watts. 1956. Equatorial Weather Malayan Meteorogical Service.

Istopo. 1968. Badai Putar Tropika. Akademi Ilmu Pelayaran Jakarta

Nathaniel Bowditch LLD. 1962. American Practical Navigator US Navy Hydrographic Office.

Otto S. Karlio. 1969. Olah Gerak Kapal

Operating Manual. 1991. Laboratorium Navigasi Elektronik BPLP Semarang.

Winstone E. Kock. 1973. Radar, Sonar and Holography

Williams, J;J.J. Higginson. 1973. Sea and Air, the Marine Environment. Naval Institute Press.

World Meteorologycal Organization. 1966. The Preparation and Use of Weather Maps by Marine, TN 72 Secretariat. 